Article

\title{
Boundary Negotiations in a Self-Organized Grassroots-Led Food Network: The Case of REKO in Finland
}

\author{
Maria Ehrnström-Fuentes ${ }^{1, * \mathbb{D}}$ and Hanna Leipämaa-Leskinen ${ }^{2} \mathbb{D}$ \\ 1 Department of Management and Organisation, Hanken School of Economics, 65100 Vaasa, Finland \\ 2 Department of Marketing and Communication, University of Vaasa, 65200 Vaasa, Finland \\ * Correspondence: maria.ehrnstrom-fuentes@hanken.fi
}

Received: 30 April 2019; Accepted: 16 July 2019; Published: 31 July 2019

\begin{abstract}
Self-organization is a term that is increasingly used to describe how engaged citizens come together to create sustainable food systems at the local community level. Yet, there is a lack of understanding of what this self-organizing activity actually means. While previous literature has addressed self-organization as an outcome of building consensus and a collective intentionality shared by the members of a group, we focus on the complex social processes involved when people with a diverse set of interests and motivations interact in the food network. In this study, we analyze what kinds of boundary negotiations emerge when grassroots-led food networks scale up. Our embedded single case study focuses on a REKO ('REjäl KOnsumtion', meaning 'fair consumption' in English) network in Finland comprising distributed local food groups and three types of actors: consumers, producers, and local administrators. We examine a conflict that arose within the REKO network in May-June 2016 when a small group of actors demanded that all local groups should implement similar rules, principles, and ethical standards. Our findings illustrate how moral, geographic, market, and power boundaries emerge in a self-organized grassroots-led food network. We further explicate the challenges that may appear within a self-organized grassroots-led food network, as it grows in scale and scope.
\end{abstract}

Keywords: alternative food network; boundary negotiation; grassroots innovation; food ethics; self-organizing community; sustainable food

\section{Introduction}

In year 2013, two trial groups were set up in the Western part of Finland to enable trade directly between local food producers and consumers. The model was called REKO, which is an abbreviation derived from the Swedish words REjäl KOnsumtion, which can be translated as fair consumption in English. In the Finnish context, the REKO network was one of the first attempts to set up an alternative food network (AFN) that organizes the trade of local food on a weekly basis, directly between local consumers and farmers. What is unique with the REKO system is that it is completely free of charge for all parties involved, as the food is traded in closed Facebook groups where farmers post what they have for sale in the Facebook group and consumers place their orders by replying to the farmers' announcements. The strategic choice to use Facebook as the sales platform has contributed to the exponential growth of the concept in Finland and beyond. Within three years after the start of the first two REKO groups with a total of 70 members, the Finnish REKO network consisted of 120 local Facebook groups with 160,000 connected members, of whom approximately 2500 were producers. Since then, the model has spread to other countries. For example, both Sweden and Norway currently have more than 100 REKO groups, with more than 100,000 members in each country. 
REKO is a type of "grassroots innovation" [1] that was originally set up by engaged consumers and local food advocates to find a solution to the detrimental effects of the conventional ways of producing, distributing, and consuming food in Finland. With 'conventional' we refer to the type of food system that is reliant on industrialised methods of food production and processing, where the distribution and trade is organised in long supply chains with anonymous actors and there is a concentration of the negotiating power in large retailers, and where success is measured by operational efficiency and not based on the social or environmental impacts of food production, distribution and consumption [2] (p. 419). Seyfang and Smith [1] define grassroots innovations as "innovative networks of activists and organizations that lead bottom-up solutions for sustainable development; solutions that respond to the local situation and the interests and values of the communities involved" (p. 585). The literature on sustainable transitions suggests that sociotechnical niches act as protective spaces where new socio-technological practices and radical alternatives can develop, grow, and eventually oust dominant unsustainable practices at the wider regime level (e.g., the conventional food system). These protective spaces provide people with the opportunity to experiment and innovate, so that new alternatives and more sustainable practices can emerge [3]. Due to its rapid and successful phase of diffusion and replication, REKO is also an illustrative example of how self-organized grassroots innovations, through replication, can grow and affect food provisioning practices beyond just the locality where the innovation initially emerged [4]. The experiences from REKO point at the complexities involved in self-organized food networks made up of loosely connected civil society actors, who do not necessarily share the same goals and values about food production and consumption [5].

These complex organizational processes can be explored through a theoretical lens of self-organization, an emerging field in the research on community-based grassroots innovations [6]. The extant literature on the topic of food has explored how self-organization may help to illuminate the diverse ways that food economies are constructed, and how the different ways of defining the meanings related to food are under constant negotiation [7] (p. 13). Nevertheless, with its focus on "a common core of ethical principles" [8], previous research on self-organization in food networks has not grappled with the complex and at times paradoxical social processes involved, when people with a diverse set of interests and motivations from multiple backgrounds voluntarily come together to enact sustainable transformations and social change [9]. Furthermore, despite the frequent reference made to the self-organizing features of grassroots initiatives, the precise meaning of self-organizing in this context remains unclear.

In this study, we highlight that boundary negotiations in self-organized grassroots-led food networks are important for three reasons. First, boundaries have an impact on who participates, or is allowed to participate, in the self-organizing activities, and on what terms. This in turn affects what kind of protective spaces for grassroots innovations are being formed, and subsequently what kind of innovations and transitions can occur within these spaces [10]. Second, a system can only be self-organized as long as it is driven by the actions of the group members, and not by external processes [6]. Thus, boundaries not only mark the distinctions between the inside and the outside (who and what practices are included/excluded in the self-organized group), they also affect the kind of relations and structures that emerge within the organization [11,12]. Third, when grassroots innovations grow and become more popular in society at large, it inevitably means that they have to cross boundaries at multiple dimensions. However, although recent literature acknowledges the importance of the boundaries in self-organization [6], there is a lack of understanding of the actual processes and dimensions that shape these boundaries and how boundary negotiations affect self-organization.

The overall aim of this study is to identify and analyze what kinds of boundary negotiations emerge during the growth of a self-organized grassroots-led food network. We analyze multifarious data from different sources (including interviews with the initial REKO actors, news articles, blog posts, meeting protocols, and Facebook discussions) and in our analysis we focus on the organizational conflict that emerged in REKO in 2016. The conflict gave rise to a heated debate in local and national REKO Facebook groups on how ethical food should be defined, and how it should be governed within 
the whole network. This naturally occurring data made it possible to identify the moral, geographic, market, and power boundaries that emerge as a self-organized grassroots-led food network grows and is confronted with multi-scalar and multidimensional complexity. Our key contribution to the self-organization literature is to provide a more nuanced understanding of the complex, and at times, paradoxical principles, and worldviews that underpin community self-organization in the context of food networks. Further, we advance the current literature by explicating the challenges and conflicts that may appear within the network during its evolving process.

The paper proceeds as follows. We start by framing our study under the theoretical discussions of self-organization, and elaborate on these theories in the context of alternative and local food networks in particular. We then justify our choice of an embedded single case study and describe our empirical materials. Next, we provide an in-depth description of our case and present our findings concerning the boundaries and their negotiations that emerged during the conflict. Finally, we discuss what our findings mean for self-organization in food networks and their long-term viability.

\section{Theoretical Framework}

\subsection{Self-Organization in Food Networks}

There is an on-going debate on the democratic principles, civic engagement, and governance of AFNs, which supposedly will lead to improved social and environmental performance within these networks [13-17]. The literature on community-led alternative food initiatives has often suggested that local actors, including producers and consumers, are seeking to change the food system by themselves as actively engaged citizens $[17,18]$. In this discussion, it is assumed that the direct interactions between consumers and producers allow for commonly shared values to emerge, which create protective niches and act as drivers for deeper structural changes in the configurations of how food is produced, distributed, and consumed at the local level $[15,19,20]$. The collective learning that is expected to arise from food networks is also often suggested to contribute to the innovative potential of these alternatives [21,22] and to steer group activities in a sustainable direction [14,19].

However, previous research on particular local food initiatives has paid little attention to the conflicts that arise from the divergent meanings and practices involved in the definitions of "good" and "bad" food, and how such contradictions impact the governance, or steering, of food initiatives in particular directions. These definitions are about "what becomes regarded as 'good' and 'bad' food and how these constructions are intimately situated and contextualised, what sets of criteria define the 'good' and 'bad' meanings embedded in particular foods, who decides on how these criteria are defined, and how food production-consumption networks are (or are not) regulated" [23] (p. 1782).

Mount [5] also points out that suggesting that AFNs would be inhabited with shared goals and values, in relation to questions about sustainability and social justice, is closer to the potential of AFNs than their reality. In fact, various studies have found that diversity in values and goals are commonplace, as the meanings attached to local (and good) food are highly dependent on the diverging and multifaceted priorities, concerns, and needs of producers and consumers [8,23-26]. Furthermore, rather than being committed to radically transforming the wider food system through active engagement, as suggested by grassroots innovations scholars, e.g., [1,17], critical scholars have pointed at the incoherencies and contradictions that some local initiatives possess, when participants are more motivated to defend local conventional farms from outside competition (termed "defensive localism" by Hinrichs [16] and Winters [27]).

This suggests that the boundaries between particular food niches are not clearly defined, as participants are not necessarily motivated by any desire to change the harms associated with the production processes often associated with conventional modes of food production. Thus, to account for the flexibility and diversity that exist within a particular organizational setting, researchers need to avoid assuming the existence of shared values and goals, and pay attention to the actual processes that set the boundaries between good and bad food in particular food networks. 
To understand these processes, there is a need to examine self-organization in grassroots-led food networks. Although self-organization is often mentioned as a mode of organizing alternative food initiatives [21,22,28], and contrasted against the hierarchical modes prevalent in conventional food systems, authors dedicated to food research have not engaged in a debate on what self-organization around food actually entails. We suggest that focusing on how boundary negotiations over values and goals are enacted in practice can provide a more comprehensive understanding of the processes involved in self-organization.

\subsection{Self-Organization in Grassroots Innovation}

The concept of self-organization has its roots in biology, physics, and cybernetics, where it has been applied to describe complex living systems and computational networks [29], and how elements in complex systems aim to achieve equilibrium without an external force (Ashby 1962 and Jantsch 1980 in [30]). In more recent debates, the concept has been applied to analyze human action in complex social systems, explaining non-hierarchical and non-centralized organizing activities within digital networks [31,32] and social movements [33-35], More recently, it has been applied to explain human-induced spontaneous and unpredictable changes in urban environments [6] and the related self-governed participatory processes at the local community level of urban planning $[30,36,37]$.

From a functional perspective, Di Marzo Serugento et al. [32] define self-organization as "a dynamical and adaptive process where systems acquire and maintain structure themselves, without external control" (p. 6). In this conceptualization of self-organization, three characteristics are stressed: organization, autonomy, and boundaries. First, the organizing elements of self-organization are what creates order and supports or restrict certain behaviors, depending on the specific functions that the organization sets out to achieve. Second, the autonomy of "the self" suggests that the organizing activities and decisions taken within the group occur without interferences from the outside. This leads to the third point about boundaries. To be able to determine whether a certain system is in fact autonomously self-organized, the boundaries of the system are important, as they separate the inside from the outside, making visible where and how the limits of self-organizing entity's autonomy are drawn. However, while this approach provides a good outline of the functional features of self-organization, it does not include the social processes of how self-organization is enforced, and how boundaries between the actors and activities inside and outside are shaped by such processes. To be able to extend the functional perspective, we discuss below how self-organization has been conceptualized as social processes in grassroots, community, and social movement organizations.

Fuchs [33] uses self-organization to define social movements as dynamic and complex self-organizing entities that are based on the permanent emergence and reproduction of their self-created protest practices and structures, which are used to advance political opposition and critique to the dominant macro-structures in society. Fuchs [33] suggests that actors engaged in these systems share particular political beliefs that motivate them in their struggles to change society. The boundaries of the movement are characterized by specific practices and identities that inform the actor's alternative view of the world and the problems that the movement seeks to address [33]. From the common actions of the people organized in social movements, emerge collective practices and events that produce and reproduce alternative values, topics, and goals in the political public sphere [33]. Simsa and Totter [34] add to the understanding of self-organized social movements by pointing out how the movements they study in Spain aim to be "open to everybody, public, egalitarian, consensus-based, and largely unstructured" (p. 286). However, the authors [34] also find that such self-organization comes with challenges, as "there are difficulties in maintaining the goal of equality and consensus-based decisions in practice due to the differences in motivation, time and knowledge of people" (p. 286).

Drawing on the work of Fuchs [33] and focusing on processes of civil participation in urban planning, Hasanov and Beaumont [30] conceptualize the core of self-organization in community-led initiatives "as a consensual balance between notions of spatial proximity, community organizing, 
and collective intentionality" (p. 234). They suggest that self-organization is characterized by a self-emerging awareness of individuals who share a specific context. This awareness, and the interrelationship between people that it embodies, are what guides the self-organizing capacities of each individual, where the process of self-organization is an outcome of "spontaneous collective performances driven by collective intentionality" [30] (p. 234).

Atkinson et al. [36] discuss self-governance in relation to societal governance of climate change, and develop a framework for how to understand self-organization as localized discussions and framing(s) of climate change, in relation to the transformation of human societies as a whole (across multiple spatial and scalar levels). They [36] suggest that the concept of self-organization, in contrast to framings of change processes through top-down governance, "introduces a human perspective and places a greater emphasis on the (face-to-face) agency of individuals and communities" (p. 204). They further argue that "self-organization allows for a focus on small-scale processes that generate possibilities for (local) collective action at multiple scales of interaction" (p. 204).

However, as previously discussed, assuming that producers and consumers possess shared intentions and goals is problematic in the context of food, partly because it blurs the contradictions and paradoxes that are common within food networks, although they are not always recognized [5]. Additionally, a focus on shared human intentions also obscures the actual concrete practices, ecologies, and materialities involved in the production, distribution, and consumption of food in particular locations [38]. Food provisioning is not just an outcome of shared values and goals; the production, distribution, and consumption of food also involve complex assemblages of practices, intentionalities and processes that "stitch together" particular "natures, cultures, spaces, and technologies in the provision of food" [38] at various scales and dimensions of interaction [39]. Goodman et al. [23] point at the challenges of defining food as good and bad based on (just) shared, socially constructed meanings and values:

Food and food ethics are relationally performative as they involve linking up of the material and constructed self with Others and Other natures in moral webs of meanings through the performances of producing, shopping, making, serving, eating, and ultimately, 'wasting'. These relational performativities of food ethics are fundamentally situated within psychological, cultural, political, social, economic, and ecological contexts, each with their own powerful moral webs of meanings and materialities created by but also shaping food ethics (p. 1784)

Therefore, to suggest that differences within alternative food networks can be overcome through increased communication [24,36], or that these networks possess a collective intentionality emerging naturally out of the socio-psychological capacity of self-organized systems [30], offers a limited view of the politics involved in the regulation of food production and consumption networks. There is more to the self-organizing processes of food networks than debating and building consensus. Human relationships with food are entangled not just with the food itself, but also with configurations, farm infrastructure, the ecology of place, and the multiple practices involved in bringing food into being. These relational qualities of food provisioning create the continually "emerging" (Williams 1977 cited in [23]) boundaries that provide food networks with structures and goals. Thus, in order to understand how more sustainable food alternatives can emerge through the processes of self-organization in grassroots-led food networks, it is insufficient to explore how humans make sense of, and negotiate the boundaries between, "good and bad" food. It is also necessary to account for how context specific ecological, technological, and economic relations shape the formation of the boundaries of food networks.

As an empirical site of research, REKO provides concrete examples of self-organization in food networks. REKO is not just local in its organizational boundaries, it is also a broader distributed network that connects a multiplicity of initiatives, each embedded in their own place-specific ecology. The virtual presence of the REKO actors in various Facebook groups makes it possible for the actors to directly participate in negotiations on collective concerns, across different geographic locations. 
This plurality of actors, locations, and practices involved, makes REKO a suitable example for exploring the boundary negotiations that impact, enable, or inhibit the emergence of a consensus about the core values, directions, and goals, both at the local level of each group and in the wider network that connects all local initiatives on a national scale. The next section explains our methodological choices and offers a more nuanced description of the case study.

\section{Methodology}

The empirical part of this study draws on the case study research design. More specifically, we apply an embedded single case study approach [40] to explore how boundary negotiations emerged and collapse in REKO.

\subsection{Case Selection}

We used theoretical sampling to select the case [41]. This meant that we chose to focus on REKO because this particular case example enabled us to illuminate the boundary negotiations that take place in self-organized grass-roots-led food networks. Thus, our aim was not to test theory, but to develop novel theoretical understandings of the issue [41]. REKO was regarded as a suitable case for the following reasons. First, because of its historic background as a particular type of community-based food initiative that has managed to grow rapidly into an extensive network at the national level, the emergence of the REKO food network in Finland gives us an opportunity to examine the challenges associated with growth processes in grassroots innovations. Second, REKO's organizational structure has been based on principles of self-organization since its initial stages, which makes it possible to analyze how self-organization manifests itself in practice. Third, the evolution of the REKO network, and the visible conflict in 2016 over how the network should be organized, provided us with rich and detailed data on the contradictions and tensions that emerge when people from different backgrounds and worldviews come together to set up common rules for a self-organized food system. It was this available data in particular that made it possible to follow and identify how boundaries are negotiated, and how they simultaneously define the self-organized entity's structure.

\subsection{Data Collection}

We collected data from multiple sources to form a rich and in-depth description of the selected case [40,42]. The data included interviews, media sources (news articles, blog posts), official documents (meeting protocols), and Facebook discussions. While our preliminary data were generated during the conflict's peak, we also leaned on materials that were collected before and after the conflict, in order to analyze its causes and consequences. Table 1 presents the empirical materials used in this study, their codings, the timeline, and the authors' roles in the process of data generation.

The first set of data consisted of interviews conducted with consumers, producers, administrators, and the original founding group of the REKO network. The consumer and producer interviews were collected from 2015-2018 and served as supplementary data, since all the informants described their reasons for being involved in the REKO network. Thus, they provided us with the means to analyze the motivations underlying REKO actor-ship. The original founding group and administrators of one local REKO group were interviewed in order to obtain a comprehensive storyline of REKO's initial stages and to uncover the original vision for REKO's foundation. These interviews represent participatory data, as the first author acted as one of the administrators in Vaasa REKO during the data gathering, and was thus involved in creating this set of data. All the interviews were recorded and subsequently transcribed. The short interviews were however collected by email. We sent a few open-ended questions to the original founding group and they answered the questions in written format. In the analysis, pseudonyms were used to protect the respondents' anonymity, but the names of the original founding actors were included with their permission. 
Table 1. Material used for analysis.

\begin{tabular}{|c|c|c|c|c|}
\hline Type of Data & Description of Data & Thread Number & Timeline & $\begin{array}{l}\text { Non-Participatory/ } \\
\text { Participatory }\end{array}$ \\
\hline $\begin{array}{l}\text { Consumer } \\
\text { interviews }\end{array}$ & $\begin{array}{l}10 \text { semi-structured interviews } \\
\text { with consumers from REKO } \\
\text { ('REjäl KOnsumtion') Vaasa }\end{array}$ & CI 1-10 & 2014-2015 & Non-participatory \\
\hline Producer interviews & $\begin{array}{l}13 \text { semi-structured interviews } \\
\text { with producers in Western and } \\
\text { Southern Finland REKO groups }\end{array}$ & PI 1-13 & 2015-2018 & Non-participatory \\
\hline $\begin{array}{l}\text { Administrator } \\
\text { interviews }\end{array}$ & $\begin{array}{l}3 \text { short interviews from the } \\
\text { original founding group in Vaasa } \\
5 \text { short interviews with the local } \\
\text { administrators in Vaasa }\end{array}$ & $\begin{array}{l}\text { FI 1-3 } \\
\text { AI 1-5 }\end{array}$ & 2018 & Participatory \\
\hline Media texts & $\begin{array}{l}12 \text { newspaper articles and } 2 \\
\text { blogtexts about the conflict } \\
\text { TedTalks presentation by } \\
\text { the founder }\end{array}$ & $\begin{array}{l}\text { Blog } 1 \text { and Blog } 2 \\
\text { TedTalks }\end{array}$ & $\begin{array}{l}\text { April-June } \\
2016 \\
2017\end{array}$ & Non-participatory \\
\hline $\begin{array}{l}\text { Official } \\
\text { documents }\end{array}$ & $\begin{array}{l}\text { Online documents on rules for } \\
\text { REKO in Finland }\end{array}$ & OD 1-3 & 2015 & Non-participatory \\
\hline $\begin{array}{l}\text { Facebook } \\
\text { discussions }\end{array}$ & $\begin{array}{l}1 \text { Vaasa REKO } \\
\text { Facebook discussions } \\
5 \text { open nationwide REKO } \\
\text { Facebook group discussions }\end{array}$ & $\begin{array}{l}\text { Vaasa FB } 1 \\
\text { Nation-wide FB 2-4 }\end{array}$ & $\begin{array}{l}\text { 8-13 June } 2016 \\
\text { 8-13 June } 2016\end{array}$ & Participatory \\
\hline
\end{tabular}

Second, using Google to search for key words referring to the 2016 conflict, we collected relevant media texts (blog posts and newspaper articles). This material resulted in 33 pages of text, providing us with a deeper understanding of the conflict. The third set of data consisted of authentic Facebook discussions. These materials enabled us to analyze the first-hand governance practices and discussions within the network. The selected Facebook conversations surfaced in two Facebook groups. The "REKO Vaasa" group was selected because it was one of the first REKO groups in Finland, and due to its rapid growth in actor-ship and sales activities, it attracted the attention of a wide range of producers. The region around Vaasa is Finland's most important farming region, featuring both organic and conventional family farms. Early on, this prompted the administrators to create rules on who was allowed to sell in the network. The other Facebook group ("REKO Local Food") operated on the national level to transmit news and discuss topics concerning REKO stakeholders. The group's status on Facebook was open, meaning that anyone could see the posts.

There are also Facebook groups that are meant only for administrators, or for administrators and producers, at the local, regional, and national levels. The first author could access these groups in her role as an administrator. In this study, we chose to not use material from those groups because of their closed status on Facebook, and because the topics highlighted here focus on the discussions that include any and all types of actors (producers, consumers, and administrators) interested in the REKO trade. Altogether, the selected material consisted of 50 pages of text. We started writing our study after the selected threads of conversations were no longer active and the actors of the Facebook groups who are quoted gave their permission to be cited. Their identities were protected with codes in the analysis.

Because we entered the field as participant observers, it is important to reflect our roles in the research process concerning its limitations and potential [40] (p. 64-65). The first author acted as one of the four administrators in the Vaasa REKO group until the end of 2018. Her engagement in REKO as a volunteer administrator was originally motivated by the hope that direct producer-consumer relations could transform agricultural practice. The second author assumed the role of a regular consumer to become familiar with REKO, which is a more distant role. While we acknowledge that our participation affects our interpretation of the findings, we believe that these positions enabled us to uncover the case in greater detail and better understand the socio-cultural meaning-making surrounding the conflict. Furthermore, our aim with this study is to support the continuous evolution of the REKO network, 
by helping it to capitalize on and diffuse the knowledge and know-how that is related to this particular form of organizing around food [43].

\subsection{Data Analysis}

Figure 1 illuminates the research process as a whole, specifying the phases of data collection and data analysis alongside with the development stages of REKO.

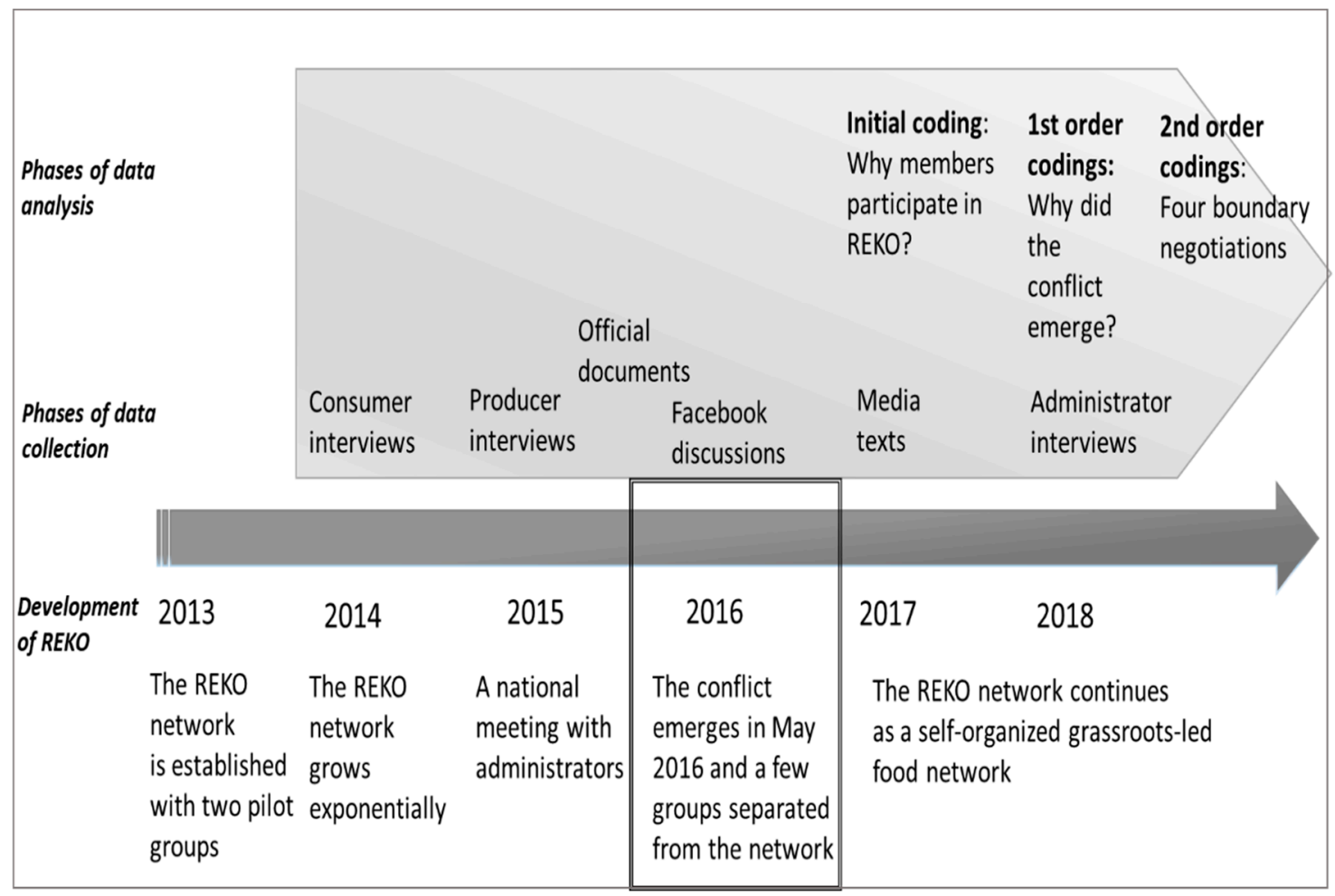

Figure 1. Research process.

As can be seen from Figure 1, we employed qualitative content analysis, going back and forth between data collection and analysis throughout the iterative research process [41,44]. We began the analysis by familiarizing ourselves with the interview data [44]. At that point, our aim was to create an initial understanding of the various reasons for why consumers and producers participate in REKO. This initial coding revealed that REKO does not have a clear or shared direction, giving us an inductive understanding of the values and goals shared by the REKO actors. We then returned to the field to gather additional interviews from the original founding group and its administrators. This helped us to sketch out the organizational features of REKO as a unique type of food organization.

In the second phase, we focused on the data sets that appeared during the conflict. These included media texts, offline documents, and Facebook discussions. We started the analysis by importing them into a Word document to obtain a comprehensive picture of the emerging themes. We kept the analysis inductive, seeking out remarks on, interpretations of the main reasons for, and reactions to the conflict. The discussions mainly revolved around food ethics and how a grassroots-led food network should operate, and this data-driven discovery led us to focus more on boundary negotiations. The emerging themes, or so-called first-order codings, were named according to the following field terms [44]: rules, competition, animal welfare, ethics in general, and trust. The second author first carried out the open codings alone, as she was not personally involved in the discussions and could thus more openly seek out the field-level themes. Both authors then discussed the codings jointly to reach a consensus on their meanings and order. 
In the third phase, we decoded the first-order codings by interpreting them against our theoretical framework [44]. At this stage, we sought to answer to the question of what kind of boundaries were under negotiation when there was conflict in REKO. Thus, the second-order codings illuminated the more abstract and theory-driven, themes emerging from the data [44]. We identified four boundary negotiations emerging in relation to REKO's self-organizing processes: moral, geographic, market, and power. By the concept of boundaries, we refer to conflicting negotiations that emerge when the actors hold opposing beliefs and interests on how the food network should operate, and which goals it should try to pursue. It should be noted that we do not regard these negotiations as mutually exclusive, but they emerged as overlapping themes across all discussions in both local and national REKO groups and among all the actors involved.

\section{Findings}

We start the findings section by first describing the emergence of the REKO network in Finland. In order to point at the varied interests involved in this particular initiative, we then describe more closely the varied motivations among the actors of REKO for joining and establishing the REKO model. We discuss the original founding groups' motivations, as well as the consumers' and producers' motivations. Next, we move to analyze the boundary negotiations that emerged during the conflict in 2016.

\subsection{Case Background: The Emergence of the REKO Food Network}

The name REKO is an abbreviation for 'Fair Consumption' (Rejäl Konsumtion) in Swedish. Inspired by the AMAP (Association pour le Maintien de l'Agriculture Paysanne) system in France, the first two trial groups were set up in Ostrobothnia, in Western Finland, in 2013. These groups consisted of dedicated consumers and producers, who after conducting a public presentation of the idea, volunteered as 'administrators' to create trial groups in their local communities.

The organizational structure of the first (and subsequent) groups consisted of administrators, producers, and consumers. The administrators were given a key role in the local groups, as they were responsible for setting up a Facebook group, deciding on a place and time for deliveries, and accepting or rejecting the group's producers and consumers. New groups were established in an ad-hoc manner, based on the volunteers' individual interests, and there thus was no control over who established new groups.

In contrast to the AMAP system, which is based on long-term seasonal contracts between consumers and producers, the REKO system is organized around weekly pre-orders placed through Facebook. Membership is open to everyone by application and it does not oblige the member to make any amount of purchases. The producers make an announcement of their weekly product offering in the Facebook group, and the consumers order their food through the comments section. The delivery of the pre-ordered food takes place weekly, or every other week, at an easily accessible and free parking lot, at a commonly agreed upon time. The delivery usually lasts for 20-60 min.

The use of Facebook for preorders contributed to REKO's popularity. Due to its unique features (easy to join and free of charge), REKO's growth, both in terms of the number of groups and members, was rapid and exponential. At the time of the conflict studied here, the network consisted of 120 groups with 160,000 members, of whom 2500 were producers. The rapid expansion of the number of groups, members, and producers created the need for more institutionalized rules for the whole network. To track and discuss administrative concerns, a Facebook group ('REKO Family') for the administrators in all Finnish groups was set up in early 2014. In 2015, a national meeting was organized in Seinäjoki to discuss whether the network should have a formal organization with a governing body. By this time, the Finnish authorities had also gained an interest in this new form of trade and requested that the movement set some common guidelines (in accordance with the law), that would serve to define and regulate the REKO organization (Correspondence with meeting organizer, August 2018). During the meeting, in which approximately 30 administrators from the groups around Finland participated 
(Correspondence with meeting organizer, July 2018), the participants decided that self-organized local groups were most effective at meeting local demands, and thus there was no need to set up a formal organization or appoint any governing bodies to control the whole network. Instead, each group would commit to the following four loosely-defined rules: (1) no middlemen allowed; (2) the food items sold should be as local as possible; (3) ethical trade-preferably organic; and (4) open and transparent operations, which meant that producers would be obliged to be open about their production methods (Official Document, OD-1).

It was the loosely defined principle of 'ethical trade - preferably organic' that later in May 2016 gave rise to a highly visible conflict in the whole REKO network. It began when a small group of administrators and producers, organized in a formally registered association called 'Farmarin Markkinat' (FM), sought to register the use of the name REKO with the authorities. According to those behind this initiative, one of the core problems of REKO was that there was no clear leader or strong organization behind the network, making it difficult to create a unified system of rules that would provide stability to what kind of trade was allowed in the group.

Moreover, the FM association took over the administration of a handful of REKO groups in the southern part of Finland, by defining and implementing ethical rules on who could sell in these groups. In a blog post, one of the most outspoken members of this group explained why FM wanted to regulate REKO's business:

With just a quick Google you can find guidelines on what is supposed to be sold there, mentioning organic, ethical production, and from as near as possible. Since the whole thing is so open that anyone can create a Facebook group with the name REKO and start selling, it creates many problems. The founders of the groups and the administrators can each interpret these loosely set guidelines in their own way. The consumers have no clear promise about what kinds of values go into the production of the food that they buy. The producers make no clear promises that certain kinds of production methods give them the right to sell their products, and the administrators are given power and responsibility for all of this. (Blog-1, 7 June 2016)

However, this "hijacking of REKO" (Nationwide REKO Facebook) was strongly condemned by many members of the network, leading to an intense online debate over the governance of ethical rules in local and nationwide Facebook groups that faded within weeks. Beyond making visible the weaknesses of the REKO system's set-up, the FM's impact on the whole REKO network was limited to a couple of groups, where the FM guidelines determined who was allowed to sell in them. In response, the original administrators of one of the local groups that was hijacked without the administrators' consent simply started a new Facebook group, and continued to operate in accordance with REKO's loosely defined ethical principles. Other than the two local groups in southern Finland that remain linked to the members of the FM association, all other local groups remain autonomous, or self-organized, in the sense that it is up to each group to decide on its own internal rules beyond the general principles set in 2015. This background of the short history of REKO, and particularly the conflict that emerged over how rules should be managed in the whole network, made this case suitable for the analysis of boundary negotiations in a self-organized grassroots-led food network.

\subsection{Motivations of the REKO Actors}

The values and principles within a food network often appear to be diversified and flexible [5]. We exemplify the conflicting values and goals of the REKO actors here, by analyzing their motivations to join REKO and participate in the REKO's activities. Table 2 illustrates the analysis. 
Table 2. Motivations of the REKO actors.

\begin{tabular}{|c|c|}
\hline Actors & Motivations (Why the Actors Are Involved in REKO) \\
\hline Co-founders & $\begin{array}{l}\text { - } \quad \text { To increase profitability for farmers } \\
\text { - } \quad \text { To create new markets and sales channels } \\
\text { - } \quad \text { To support the development of organic farming }\end{array}$ \\
\hline Trial group admins in Vaasa & $\begin{array}{l}\text { - To know where the food comes from } \\
\text { - To support local farms } \\
\text { - To raise consumer awareness about local food } \\
\text { - } \quad \text { To have access to local and organic food without having to visit the farms } \\
\text { - To change the world of food in a concrete way } \\
\text { - To shape the Finnish food system through direct sales }\end{array}$ \\
\hline Producers in trial groups & $\begin{array}{l}\text { - To access new markets } \\
\text { - } \quad \text { To increase profits } \\
\text { - } \quad \text { To educate consumers about local food } \\
\text { - To set up new business } \\
\text { - } \quad \text { To convert production methods to more small scale methods }\end{array}$ \\
\hline Consumers in Vaasa REKO & $\begin{array}{l}\text { - To obtain high-quality, fresh, and tasty food } \\
\text { - To know where the food comes from and what they eat } \\
\text { - To have access to local and organic food at the same time in one place } \\
\text { - To support local farmers and avoid intermediaries (e.g., retailers) in the food chain } \\
\text { - To meet friends } \\
\text { - To educate children to eat in a healthy and responsible way } \\
\text { - To be able to obtain local food for a reasonable price }\end{array}$ \\
\hline
\end{tabular}

From the beginning, REKO's co-founders had different motivations for establishing REKO. The organic farmer Thomas Snellman, who invented the idea while visiting AMAP-style local food markets in France, saw REKO primarily as a solution for many of the problems associated with the dominance of food retail in Finland (FI-1 August, 2018). For some time, small-scale food producers had encountered financial difficulties in Finland, as the original founder describes below:

Every week in Finland five farmers quit their activity because they cannot make a living. [... ] Supermarkets and wholesale are very strong in this part of the world and the farmer's power to negotiate is not so good. At the same time, six or seven years ago, in our region, people started to ask for locally produced organic food. And they shouted about it but they could not find it anywhere [ . . . ] In 2012, I participated in an AMAP delivery in France by accident. [ ... W When I saw the system and the exchange of products between producers and consumers, I was overwhelmed by this ingenious idea and so I thought that when I returned to Finland I would like to create something similar. (Snellman, Ted Talk presentation, 2017)

The other two co-founders hoped that REKO would increase the interest in organic food production in Finland, and saw it as a possibility of establishing a local sales channel that did not exist within the existing retail trade system. Their views are exemplified in the following quotation:

The structure of retail in Finland has made it very difficult in practice to start up new small-scale food businesses, since there is no other channel to reach the consumers than through the established supermarket chains. Even if some consumer groups had an increased interest for local food, it was not enough because there was simply no sales channel. That is why a new channel for direct sales was needed and that channel was created through REKO. (FI-2 August, 2018) 
Those who later participated as volunteer administrators in the first two trial groups (mostly consumers) also had diverse motivations for establishing this alternative channel for sales of local food, as exemplified by the following two quotations:

It was my own interest to know more about where the food comes from as well as the feeling of being part of something valuable for the producers, whose future seemed insecure and unprofitable, despite their high-quality products, and for other consumers who would start to understand what good products this region has and start to consume more consciously and healthily. (AI-1 August, 2018)

This was an opportunity to do something concrete and initiate some sort of change. I was tired of just discussing and talking. I wanted action [ ... ] I wanted to be part of a movement that creates better, cleaner and more sustainably produced food by supporting and giving space to small farms. (AI-2 August, 2018)

In interviews with consumers and producers in the same trial groups (conducted in 2015, 2017, and 2018), their answers for why they decided to join the network varied greatly. While some consumers stressed the ecological aspects and superior quality of food sourced through REKO, others wanted to buy food with a lower price than that of similar products in the super markets (CI 1-10). Many consumers reported that they bought local food from REKO producers because they regarded local food as fresh and tasty, and preferred to know the precise origin of the food they were eating. For some consumers, REKO provided an easily achievable outlet for realizing ethical and sustainable food consumption behaviors. Social factors were also discussed, as some consumers wanted to get to know the producers and be part of REKO's community spirit.

Producers stated that they were motivated not just by wanting to know the people who consumed their food, but also by the potential economic gains they could achieve by selling directly to consumers. The producers reported that they joined REKO primarily because of economic factors, such as receiving a higher price for their products and offering products that could not be sold through the conventional supply chain (P1 1-13). Some producers also reported that they appreciated the direct customer contact and the possibility to discuss their products' value instead of the price (P1 1-13).

Because of the variety of reasons for engaging in the trial groups, the questions about what kinds of producers should be allowed in, and what kind of rules should be applied in terms of who was allowed to sell in REKO, were discussed during the early planning meetings (FI-3 August, 2018). However, the first administrators quickly realized that it was practically impossible to restrict participation in the early stages, simply because of the low interest shown by most local producers, as explained by Snellman:

During the planning stage, we primarily struggled to find anyone who wanted to join. The concept was untested and difficult to concretize for many. It was my and Jonas Harald's personal networks that played a crucial role in attracting any producers at all. In principle, anyone that wanted to participate was allowed in, and it was gratifying to see that the organic producers were over-represented. (FI-1 August, 2018)

This plurality of motivations among the network actors, in the later stages of REKO's expansion, led to confusion and conflict for the people who required clarity on what kinds of principles and rules should be permitted in the network. This resulted in network-wide discussions, which made it possible for the identification of how and what kind of boundaries are negotiated during times of conflict. These boundaries are presented in the analysis below.

\subsection{Boundary Negotiations in REKO}

The first boundary negotiation identified in the analysis occurred in relation to the moral boundaries. By moral boundaries, we mean the shared worldviews, such as political and ethical 
beliefs, which motivate the actors to join the network in order to change society [33]. In the current context, moral boundaries are closely related to how the REKO actors make sense of what "good" food is [23]. They are thus highly dependent on how the actors' diversified priorities and needs $[5,24]$ are linked up in moral webs of meaning, through the practices involved in the network (producing, shopping, consuming food) [23]. The following excerpts exemplify how two producers discussed the ethics of food. While the first producer asked for more specific criteria in defining ethical food production, especially in the context of animal farming, the other trusted that the official standards for practices such as organic farming, gave useful frames for defining ethical methods in food production:

When does the number of animals in a production unit become intensive farming? And is it ethical to disregard that animal feed from non-organic farms can include GMO and glyphosates? [ ... ] The ethical rhetoric is media sexy but changeable and easily one-eyed. (Producer, Nationwide FB-3, 13 June 2016)

The organic standard already offers reliable standards for those interested in ethical production: the consumer that wants to support ethical production knows that the organic label criteria in Finland fulfil the ethical production attributes in many different ways. That is why the definition coming from the authorities in this case is enough. We do not need an extra system or any third-party criteria. (Producer-administrator, Nationwide FB-3, 13 June 2016)

These quotes illustrate the contradictions in meanings that emerge from the participants' diverse interests and priorities. These contradictions also emerge from the myriad of discourses, regulations, and ways of defining and perceiving the ethics of food, in communities that have been historically separated by the long food supply chains that are imposed by conventional food systems [5]. The first quote suggested that the perceptions of food ethicality is influenced by media trends, while the latter quote suggested there was no need to formulate new internal regulations within the network beyond the national regulations on organic trade. In either case, the negotiation of moral boundaries between REKO and other forms of provisioning food is not just an outcome of the interactions of producers and consumers in direct exchange (of products and information) within the REKO network, but is also influenced by the moral webs of meanings and ethical prioritization processes that govern food choices in society at large. This contradiction points at the problem of defining the actual moral boundaries of grassroots-led networks. The moral webs of meanings that circulate within the network are not necessarily an outcome of the self-organized processes of the actors involved in the network, but influenced by external sources (e.g., organic certification schemes, media discourses) that regulate the "good" practices of food production.

The second boundary formation that we identified related to the specific geographic context, or the available farm and place-based ecologies that limit or enable the establishment of direct trade between local producers and consumers. In essence, the geographic boundary negotiations point at the difficulties of not just defining the moral boundaries of 'local' food, but also of accommodating boundaries to the concrete materiality of local farming and consumption practices. Many actors stressed the differences that exist in terms of the availability of small-scale and organic production systems in different places, and how this affected what kind of products and producers should be allowed to trade in the local groups. Due to the transformations of the rural landscape generated by the industrialization of agriculture [5], not all locations in Finland have farming communities that have the kind of products that are attractive at local food markets. Setting strict national standards can thereby hamper the emergence of local REKO groups, if there is insufficient flexibility to accommodate and negotiate rules according to local circumstances. The debates also suggested that the ways people make sense of, and prioritize, the different attributes of good food influences and are influenced by the local circumstances, as illustrated below:

REKO's policy is that food should be as local as possible, but local food is a flexible concept depending on where you live. In Lapland, locally produced may mean a 150-km radius, while 
in South Finland the distance may be $50 \mathrm{~km}$. Place-dependence and situation-dependence is important in REKO. (Consumer-administrator, Vaasa FB-1, 9 June 2016)

If there is such production that is ethically sustainable, ecological, animal friendly, self-sufficient, and on all criteria clearly better than conventional average production methods, such products should be allowed, shouldn't they? What if in a particular area this kind of production doesn't exist, but in the neighboring community it does; should the REKO-actors only receive the home community's intensively produced cheap products, or should they bring in producers from elsewhere? Right now, the situation is such that what is allowed differs from place to place and in some places REKO also allows intensive farming representatives [ ... ] Of course the local food principle must be a priority but not at the expense of ethicality. (Consumer, Nation-wide FB-2, 13 June 2016)

The consumers are different and so the values of the consumers are different. For some the ethics of the production is important for some it is the price and the quality [ ... The ethics of production is the most important thing in REKO but I would argue that regionally we go too far if we start to prioritize ethics at the expense of supply. The administrators must be awake so that they do not pressure for so much ethicality [that it] restricts the availability of products. (Producer, National FB-4, 16 June 2016)

These quotes address the difficulty of setting a collective intentionality [30], or a shared sense of direction, on what the wider national REKO network should set out to achieve [32], when the concrete materials and locally constructed moral webs of meaning of each REKO group vary greatly. This boundary negotiation, around how far products and producers should be allowed to travel, also points at the concrete material challenges that new grassroots-led food networks face in finding appropriate products and producers, when particular forms of food production have disappeared from the immediate local sphere [5].

The third boundary negotiation emerged in relation to market boundaries between conventional and REKO market offerings, or what kind of "alternative" attributes the products and producers should have that are different from the offerings in the supermarkets, in order to be able to access the REKO network. This boundary points at the challenges of creating a "protective space" or a niche within the wider sociotechnical regime of the conventional food system. These niches do not exist in isolation, but are "hybridities" which interact and co-evolve with the prevailing food system [5]. The negotiations centered around the question of whether intensive and large-scale producers, or only small producers that could provide a clearly distinguishable alternative product to the products available in conventional markets, could be allowed to sell their produce in the local groups. Those supporting small-scale local production saw that REKO needed to create a clear boundary against the product offerings in the conventional market, in order to attract both consumers and producers to the network:

The consumers have an automatic expectation that the food sold through REKO is ethically produced. The producers who prioritize ethicality in their production should also have some guarantees that they do not have to compete with cheaply produced products in the REKO groups, since that would be the last kiss of death for them. (Consumer, Nation-wide FB-2, 9 June 2016)

The same consumer also suggested that setting clear market boundaries would create an incentive for Finnish farmers to change their production methods, as only by changing their farming methods could they access the REKO trade. In fact, some of the people who engaged in this negotiation saw clear market boundaries as a necessity if REKO was going to be able to stand for a distinguishable alternative to dominant forms of food production $[7,15]$. This argument can be seen in the next blog quote: "REKO ignores the possibility to communicate the message to the Finnish farming community. 
If REKO would include only ethical produce, it would gradually increase interest in ethical farming. Now, the message has been watered down" (Blog-1, 7 June 2016).

The opposing views argued that REKO should not be a closed system, but a kind of food network that exists within the dominant food markets and is thereby also able to compete in price against the dominant food retail sector. Some people suggested that REKO should guarantee a fair pricing level, as consumers may prefer supermarkets if REKO only sells "expensive" products:

If REKO would accept only 'expensive' food (many consumers still look at the price of the product), we would risk most consumers leaving the system and returning to Prisma and Citymarket [two major supermarket chains in Finland]. How could ethical producers in REKO benefit from this? Also, their customer volumes would decrease. Is that what we want? (Consumer-administrator, Nationwide FB-2, 9 June 2016)

It's funny that people want REKO to be a single market where only small number of producers can sell. [ ... ] If the battery eggs would be excluded do you really think that everybody would buy organic eggs that are double in price? I don't think so. (Consumer, Nationwide FB-2, 10 June 2016)

This boundary negotiation points at the challenges that this type of niche organization faces, as it is embedded in a market-regime where product pricing is determined by the processes and configurations set by food retail actors in the conventional supply chain. This creates a problem where the local groups are faced with two options: whether to allow inexpensive (unsustainable) offerings which lure more people into the system through their affordability, or whether the groups should remain strictly dedicated to the ideals of small-scale and environmentally sound farming practices, that establish clear boundaries against the conventional market.

This boundary formation between (un)sustainable niche/regime markets creates contradictions that a self-organized system with no clear leader or overarching goal will find hard to resolve. If the network as a whole has a clear, outspoken, and morally informed value system based on certain ideals (i.e., small scale, environmentally sound practices), then the pricing issue would be of secondary importance. However, as the discussions on moral boundaries previously revealed, the REKO network lacked pronounced and shared moral values in terms of the product offerings, and thus conflicts from diverging (consumer and producer) expectations were bound to emerge.

Finally, we identified a boundary regarding power configurations, or who has the power to decide what within the network. These negotiations can be divided into two different themes: (1) the (limited) power of consumers in the internal market transactions, and (2) the power of administrators in each local group. The negotiations related to the consumer roles were focused on whether consumers were active and/or passive actors in shaping the REKO market, through their consumption patterns. The analysis demonstrates that consumers were defined either as empowered actors who were capable of making enlightened choices when buying food, or people who only had limited opportunities to make "good" and ethical food consumption choices. These opposing views are illustrated in the following quotations:

I think that the consumers are enlightened and capable of making their own decisions, and the market also tells the producers whether they are in the right place, if they are honest about their production, which I believe most are. (Consumer-administrator, Nationwide FB-3, 13 June 2016)

If only good will and education were enough, we wouldn't have an agriculture based on intensive practices that turns both producers and animals into slaves, or grocery stores filled with food farmed with the cheapest possible poison-nor consumers that buy it with enthusiasm. (Consumer, Nationwide FB-2, 13 June 2016) 
The quotes indicates that while consumers were regarded as enlightened subjects, the structures of food production often remain locked into particular socio-technological configurations of the wider agricultural sector, which cannot be easily changed through just consumer choices. This is a problem that was also identified by Mount [5], and may create challenges for the network to rely on consumers to be the drivers of change towards more sustainable practices, especially when the consumers' motivations and values vary greatly within the group. The data also contained other examples of problems related to the roles of administrators in the local groups. One conflict emerged when a consumer wanted to raise the problem of the presence of a battery egg producer in the local group. This resulted in a conflict where the administrator and the consumer were unable to continue discussing the concern, and the consumer was disallowed from being involved in the group:

This is exactly the problem; I was kicked out and excluded from the group. So, the discussions between myself and the administrators did not have any impact. The producer of battery eggs happens to be a friend of one of the administrators-although the administrator runs an organic farm herself. (Consumer, Nationwide FB-2, 9 June 2016)

These types of conflicts, between actors with different roles in the network and the administrators' capacity to "shut out" participants with "inconvenient" opinions from the local REKO groups, point at the dangers of assuming that self-organization automatically fulfills some principles and ideals of democratic will-formation [34]. Research on self-organization often stress the nature of consensus driven decision-making being based on non-hierarchical relations, where the processes of decision making are egalitarian and open to all actors involved (see for example $[34,36])$. The excerpt above suggests that the online conversations and the practices within particular REKO groups do not offer any safeguards for such democratic ideals in the decision-making processes. The REKO model does not include processes that make administrators in the individual local groups accountable for the decisions they make. Consequently, it is important to note that what is initially perceived as dynamic self-organized processes can also evolve into hierarchical organizations. There is also a risk that the debate itself creates communicative hierarchies between those who are more or less articulate on the topics being debated [45]. Thus, the extent to which self-organized decision-making processes can live up to ideals of democracy is still dependent on the factors of whose voices are being heard, who engages in the debates, and how the concerns raised are taken into account in the decisions that affect the future of the local groups and the wider network.

\section{Discussion}

In this study, we conceptualized REKO as a self-organized grassroots-led food network that, through its virtual presence in both local and national Facebook groups, connects multiple local grassroots initiatives, each embedded in their own specific context, to a nation-wide network. The early evolution of the REKO network followed a self-organized process in the sense that the network's emergence was not based on a planned or controlled strategy of the founding members, but through the spontaneous interaction of people who wanted to see some change in how food was being produced, distributed, and consumed in Finland. Thus, consistent with self-organization definitions in previous literature [6], new nodes in the network emerged through spontaneous and unpredictable engagements of the volunteer local community members in different parts of Finland, who created replications of the two initial REKO trial groups established in 2013. However, the actual motivations for joining the REKO network varied greatly among the participants, which meant that the change that they envisioned was not based on commonly shared values and beliefs, but was informed by divergent priorities and interests. Additionally, in contrast to previous studies that underscored the consensual dimensions of self-organization $[12,33,34,36]$, the actual act of self-organizing in REKO, particularly as the network grew in scale and scope, pointed at social processes that were marked by conflicts and contradictions. These conflicts and contradictions arose because of the diverse motives and goals held by the participating parties. 
Our analysis of the REKO network highlights that a grassroots-led food network can exhibit features of self-organization despite the lack of a shared collective intentionality, or commonly shared values and beliefs, that steer the organization in a particular direction. Instead, in contexts that were marked by divergent and contradictory motivations and goals, the self-organization was an outcome of negotiations that occurred in the organization's moral, geographic, market, and power boundaries. The boundaries were not static, but shaped by the psychological, cultural, economic, and ecological contexts [23] of the actors involved in negotiating the rules and enacting the trade within each local group.

In essence, the outcomes of conflicts and boundary negotiations set the limits of what the organization could achieve, providing it with goals that pointed in multiple directions. Without leaders or clear definitions on shared values and desired common goals, the direction that the network or local groups pursued could not be controlled or guaranteed to encourage improved and sustainable patterns of production and consumption. In fact, as seen in the debates over battery cage eggs, some groups chose to defend the existing local conventional producers, by defining their boundaries in a way that allowed conventional intensive forms of production to compete with small-scale, organically certified farms [16,27]. However, creating fixed and deterministic boundaries could have made local groups incapable of adapting to the existing local context. Thus, the boundary negotiations not only defined the limits of the organization, but also the possible transformations that could occur within the protective space of the niche alternative.

The connection between local groups and the nationwide network created further challenges for self-organization. As each local group enacted its own context specific self-organization (through boundary negotiations) based on the diverging moralities, geographies, market relations of the involved actors, as well as on the power relations that shaped the outcomes of the boundary negotiations, this meant that the directionality of the wider network could not be governed or steered in any particular direction.

In REKO, it was this ambiguity over the direction of the whole network that motivated the FM association to propose the implementation of stricter nationwide rules regarding what kind of products and producers should be allowed in the system. Streamlining boundaries for all network entities would have made it possible to create a clearer distinction between the niche and regime markets, privileging particular ways of producing and consuming food that were not possible within the regime level of conventional food system configurations. However, streamlining the boundaries of the whole network would have decreased the local groups' capacity to adapt to their place-specific "relational performativities" [23] (p. 1784) between producers, consumers, materialities, and ecologies, which is what made particular 'good' foods come into being in those particular places. As the founder of REKO noted in one of the discussions in the Facebook groups, had the first trial groups implemented these types of standardized rules, there would not have been any REKO network to speak of. What he meant by that statement was that if the emerging REKO system had not adapted to the kind of food realities that existed in different places, there would not have been enough producers delivering the "right" kind of foods, and consequently not enough consumers interested in this type of alternative market. Thus, self-organization is more than just setting boundaries to the outside world, it also includes negotiations on what is feasible based on the circumstances in each entity of the network. Centralizing the boundary negotiation of self-organization creates entities that are not adaptive to the feasibility of each entity of the network.

Our findings also point at the hybridity of boundaries in grassroots organizations. The boundaries that are negotiated in the network are not detached from the outside world, but are very much shaped by the psychological, cultural, political, social, economic, and ecological configurations [38] of the actors and places involved. Consistent with previous critique on the impossibility of social movements emphasizing local practices and self-determination to completely detach themselves from the larger politico-economic context in which they operate [45], this hybridity of boundaries also raises questions about the actual autonomy of self-organized alternatives to enact radical change within 
the 'protective' space of grassroots-led food networks. Neither moral webs of meanings nor niche market relations can be completely disconnected from the conventional food regime's structures, practices, and meanings [45]. Public discourses on what kind of foods are desirable in the wider society also influence the perceptions and priorities of food provisioning in the niche alternative [5]. Many producers are obliged to buy supplies and sell their produce through both conventional and alternative sales channels $[39,46]$. They must therefore not only conform to the consumer demands in the niche alternative, but also have their farm practices structured by dominant market forces. Consumer priorities of prices and products are also directly influenced by price formation and product offerings in the conventional market [5].

The hybridity of boundaries has consequences for the transformative power of self-organization. As Seyfang and Haxeltine [4] have previously noted, "the main challenges faced by grassroots innovations are related to the struggle to maintain a viable sustainable socio-technical space within a wider unsustainable regime" (p. 384). In the case of REKO, our findings suggest that the unsustainably low food prices in the conventional market creates a situation where the fair prices of the more sustainable alternatives in the network are deemed to be unsustainably high by the larger public. Thus, the interdependence that exists between expectations within the niche and the wider regime also limits the kind of transformations that can occur through self-organizing practices that are partially bound to existing structures and unsustainable food provisioning trajectories. The challenge for those involved in the negotiations of all the network's boundaries is to maintain a balance between insisting on change while remaining dependent on dominant and competing practices in the wider society. This is particularly challenging in a self-organized network that lacks the strong leadership and common visions that would steer the self-organized activities in a particular direction.

This brings us to our last point about the boundaries of consumer and administrative power within the network. We identified two boundary dimensions that referred to the power that supposedly consumers have (or not) in terms of changing the system based on their enlightened consumer choices, and the power that local administrators have in terms of deciding the criteria and rules that regulate the local REKO groups.

The limits of relying on consumer power to "enlist ordinary people into broader projects of social change" has been widely discussed in the AFN literature (for an overview see [23]). This study suggests that although consumers may have a commitment to particular ethical concerns, they cannot possibly attend to all the contradictions in meanings and practices through their purchasing choices. Our findings from the online discussions over consumer power also pointed at the limited influence that consumers have to push for radical change in a farming context that is primarily shaped by legal regulations and powerful actors in the conventional food system. A self-organized system, where transitions to more sustainable practices are envisioned to emerge based on short-term economic exchange commitments between individual producers and consumers, limits its own collective capability to a very constricted space of innovation, which is constrained by consumer-producer relations. Considering the large number of people connected to the REKO network, the system possesses an untapped potential of more radical forms of grassroots innovations. This potential could be realized if the network members were to build other forms of mutual engagements that are not defined by their roles as food producers and consumers, but by their roles as responsible civil society citizens seeking radical change to current unsustainable regime-level practices. Nevertheless, the mere existence and growth of the REKO network does demonstrates that consumers, together with the producers, have a certain degree of collective agency to alter food provisioning practices that were previously completely controlled by dominant actors in the conventional food system.

In terms of the identified challenges of administrator power, it is important to point out that self-organization should not automatically be assumed to be horizontally constituted on the ideals of democracy, which has been suggested by social movement and urban planning scholars $[34,36,37,44]$. Establishing the people with the capacity to express their opinion and set the boundaries is an outcome of the negotiating capabilities of the actors involved in the network [47], and the contextual circumstances 
that shape the group's organizing practices. In the current way that the REKO network is set up, there is little room to challenge the power of local administrators who act against the will of the network's other members, besides raising questions in online debates. This makes the nodes in the network vulnerable to "unreflexive" [14] approaches to the definitions of the boundaries of the alternative organization. Increasing the collective decision-making power would mean that all actors involved should have a say in the boundary negotiations. This in turn increases the possibility that decisions reflect a diversity of interests, interpretations, and priorities [5]. Only open and communicative forms of boundary negotiations can provide the network with the flexibility and adaptability needed to continuously evolve based on self-organization. The reflexive mode of interaction also counters the risks of having a small unrepresentative group setting static and fixed boundaries, whether local or network-wide, that hide the ambiguities and contradictions inherently linked to deterministic definitions of 'good' food and their boundaries $[5,14]$.

The question about the collective decision-making structures that influence power boundaries within the organization is a crucial question for the further development of the REKO network. How each local group negotiates the boundaries of decision-making power influences the kind of transformative power that can be triggered to facilitate the development of the grassroots-led initiative in a sustainable direction. Until now, research has been silent on the issue of power in grassroots innovations $[9,10]$. To create a more comprehensive understanding of the transformative power of grassroots-led self-organization, future studies should further investigate the dynamics of power relations and self-organized leadership in research settings similar to that of the REKO network.

\section{Conclusions}

The research on grassroots innovations within food often stresses that people come together at the local level to organize alternative food projects because of their shared understanding of the harms of the dominant food system $[18,19]$, and that the shared meaning about the value of the alternative local food originates from the direct relationships formed between producers and consumers $[15,19]$. However, the findings from our analysis of the REKO network demonstrate both the normative heterogeneity that may exist among key participants from the establishment of a grassroots-led food network, and the conflicts that may occur as such a heterogeneous food network grows and replicates in multiple locations.

Our key contribution is towards the self-organization literature, as we extend current understandings of self-organization [32] by suggesting that a grassroots-led food network can exhibit features of self-organization, despite the lack of collective intentionality and shared behaviors or expectations. Hence, we argue that self-organization in these types of food networks is an outcome of the negotiations that occur within the boundaries of the networked organization. By doing so, we also contribute to the extant literature on grassroots innovations [4,30], by extending the understanding of the challenges of managing expectations in a social network that is made up of a diverse set of actors but lacks a pronounced vision or clear leader. The identified boundary negotiations highlight the complex and sometimes contradictory social processes, through which the actors make sense of the network's moral, geography, market, and power boundaries. We argue that these processes are crucial for all parties involved to understand when the network scales up, in order for them to navigate and/or disentangle possible conflicts that may emerge in the network.

This study was primarily concerned with identifying the contradictions and conflicts that emerge, as grassroots innovations grow and engage in the boundary negotiations that define their particular characteristics. The aim of the study was therefore not to provide solutions to how to manage conflicts, or provide policy implications based on our findings. Instead, we pointed at how conflicts and boundary negotiations influence self-organization in dispersed networks. To address the issues of how to cope with conflicts in grassroots-led networks, and how to provide direction to a dispersed network consisting of actors with multiple divergent interests, values, and beliefs, we suggest that 
future research should connect the grassroots innovation literature with the emergent understandings of network management in business contexts (for an overview see [48]).

We have focused on one embedded case and analyzed the empirical materials generated during specific times and locations. Therefore, the current findings cannot be generalized to other food networks without considering the contextual conditions. Future research could examine more carefully the processes, practices, and activities that can support different types of grassroots-led food networks to overcome the self-organizing challenges they face. We also call for future research on questions regarding the power constellations in the self-organized networks that presumably set out to achieve specific results. How is democracy guaranteed and who is held accountable for decisions about specific goals in the food networks that consist of multiple nodes of local self-organized groups?

Author Contributions: Both authors contributed equally to the conceptualization, methodology, formal analysis, investigation, original draft preparation, and review and editing of all previous versions of this paper.

Funding: This research was partially funded by Academy of Finland, grant number 296883 and 317910.

Acknowledgments: We thank the anonymous reviewers and editors for their supportive comments that helped us improve the final version of this paper. We would also wish to thank David Grant and Steffen Böhm for their helpful comments on earlier versions of this paper.

Conflicts of Interest: The authors declare no conflict of interest. The funders had no role in the design of the study; in the collection, analyses, or interpretation of data; in the writing of the manuscript, or in the decision to publish the results.

\section{References}

1. Seyfang, G.; Smith, A. Grassroots innovations for sustainable development: Towards a new research and policy agenda. Environ. Politics 2007, 16, 584-603. [CrossRef]

2. Tregear, A. Progressing knowledge in alternative and local food networks: Critical reflections and a research agenda. J. Rural Stud. 2011, 27, 419-430. [CrossRef]

3. Geels, F.W.; Schot, J. Typology of sociotechnical transition pathways. Res. Policy 2007, 36, 399-417. [CrossRef]

4. Seyfang, G.; Haxeltine, A. Growing grassroots innovations: Exploring the role of community-based initiatives in governing sustainable energy transitions. Environ. Plan. C Politics Space 2012, 30, 381-400. [CrossRef]

5. Mount, P. Growing local food: Scale and local food systems governance. Agric. Hum. Values 2012, $29,107-121$. [CrossRef]

6. Hasanov, M.; Zuidema, C. The transformative power of self-organization: Towards a conceptual framework for understanding local energy initiatives in The Netherlands. Energy Res. Soc. Sci. 2018, 37, 85-93. [CrossRef]

7. Veen, E.J. Fostering community values through meal sharing with strangers. Sustainability 2019, 11, 2121. [CrossRef]

8. Rossi, A. Beyond food provisioning: The transformative potential of grassroots innovation around food. Agriculture 2017, 7, 6. [CrossRef]

9. Smith, G.; Seyfang, A. Constructing grassroots innovations for sustainability. Glob. Environ. Chang. 2013, 23, 827-829. [CrossRef]

10. Smith, A.; Stirling, A.; Bekhout, F. The governace of sustainable socio-technological transitions. Res. Policy 2005, 34, 1491-1510. [CrossRef]

11. Westley, F.; Antadze, N.; Riddell, D.J.; Robinson, K.; Geobey, S. Five configurations for scaling up social innovation: Case examples of nonprofit organizations from Canada. J. Appl. Behav. Sci. 2014, 50, $234-260$. [CrossRef]

12. Pitt, H.; Jones, M. Scaling up and out as a pathway for food system transitions. Sustainability 2016, 8, 1025. [CrossRef]

13. Dupuis, M.; Gillon, S. Alternative modes of governance: Organic as civic engagement. Agric. Hum. Values 2009, 26, 43-56. [CrossRef]

14. Goodman, D.; Dupuis, M.; Goodman, M.K. Alternative Food Networks: Knowledge, Places and Politics; Routledge: New York, NY, USA, 2011.

15. Hunt, A. Civic Engagement in Food System Governance: A Comparative Perspective of American and British Local Food Movements; Routledge: New York, NY, USA, 2015. 
16. Hinrichs, C. The practice of politics of food system localization. J. Rural Stud. 2003, 19, 33-45. [CrossRef]

17. Renting, H.; Schermer, M.; Rossi, A. Building food democracy: Exploring civic food networks and newly emerging forms of food citizenship. Int. J. Soc. Agric. Food 2012, 19, 289-307.

18. Seyfang, G. Ecological citizenship and sustainable consumption: Examining local organic food networks. J. Rural Stud. 2006, 22, 383-395. [CrossRef]

19. Kneafsey, M.; Cox, R.; Holloway, L.; Dowler, E.; Venn, L.; Tuomainen, H. Reconnecting Consumers, Producers and Food: Exploring Alternatives; Berg Publisher: Oxford, UK, 2008.

20. White, R.; Stirling, A. Sustaining trajectories towards sustainability: Dynamics and diversity in UK communal growing activities. Glob. Environ. Chang. 2013, 23, 838-846. [CrossRef]

21. Ingram, J.; Maye, D.; Kirwan, J.; Curry, N.; Kubinakova, K. Learning in the permaculture community of practice in England: An analysis of the relationship between core practices and boundary processes. J. Agric. Educ. Ext. 2014, 20, 275-290. [CrossRef]

22. Maye, D. Examining innovation for sustainability from the bottom up: An analysis of the permaculture community in England. Sociol. Ruralis 2018, 58, 331-350. [CrossRef]

23. Goodman, M.K.; Maye, D.; Holloway, L. Ethical foodscapes? Premises, promises, and possibilities. Environ. Plan. A Econ. Space 2010, 42, 1782-1796. [CrossRef]

24. Cox, R.; Holloway, L.; Venn, L.; Dowler, L.; Hein, J. Common ground? Motivations for participation in a community supported agriculture scheme. Local Environ. Int. J. Justice Sustain. 2008, 13, 203-218. [CrossRef]

25. Lamine, C. Settling shared uncertainties: Local partnerships between producers and consumers. Sociol. Ruralis 2005, 45, 324-345. [CrossRef]

26. Morris, C.; Kirwan, J. Ecological embeddedness: An interrogation and refinement of the concept within the context of alternative food networks in the UK. J. Rural Stud. 2011, 27, 322-330. [CrossRef]

27. Winters, M. Embeddedness, the new food economy and defensive localism. J. Rural Stud. 2003, 19, $23-32$. [CrossRef]

28. Morgaues-Faus, K. Reframing the foodscape: The emergent world of urban food policy. Environ. Plan. A Econ. Space 2016, 47, 1558-1573. [CrossRef]

29. Maturana, H.R.; Varela, F.G. Autopoiesis and Cognition: The Realization of the Living; Boston Studies in the Philosophy of Science; Springer: Dordrecht, The Netherlands, 1980.

30. Hasanov, M.; Beaumont, J. The value of collective intentionality for understanding urban self-organization. Urban Res. Pract. 2016, 9, 231-249. [CrossRef]

31. Bennett, W.L.; Alexandra Segerberg, A. The logic of connective action. Inf. Commun. Soci. 2012, 15, 739-768. [CrossRef]

32. Serugento, D.G.; Gleizes, M.P.; Karageorgos, A. Self-organization in multi-agent systems. Knowl. Eng. Rev. 2005, 20, 165-189. [CrossRef]

33. Fuchs, C. The self-organization of social movements. Syst. Pract. Action Res. 2006, 19, 1-37. [CrossRef]

34. Simsa, R.; Totter, M. Social movement organizations in Spain: Being partial as the prefigurative enactment of social change. Qual. Res. Organ. Manag. Int. J. 2017, 12, 280-296. [CrossRef]

35. Chowdhury, R.; Kourula, A.; Siltaoja, M. Power of paradox: Grassroots' organizations' legitimacy strategies over time. Bus. Soc. 2018. [CrossRef]

36. Atkinson, R.; Dörflerb, T.; Hasanov, M.; Rothfuß, E.; Smith, I. Making the case for self-organization: Understanding how communities make sense of sustainability and climate change through collective action. Int. J. Sustain. Soc. 2017, 9, 193-209. [CrossRef]

37. Horelli, L.; Saad-Sulonen, J.; Wallin, S.; Botero, A. When self-organization intersects with urban planning: Two cases from Helsinki. Plan. Pract. Res. 2015, 30, 16. [CrossRef]

38. Goodman, M.K.; Sage, C. Food transgressions: Ethics, Governance and Geographies. In Food Transgressions: Making Sense of Contemporary Food Politics; Goodman, M.K., Sage, C., Eds.; Routledge: London, UK, 2014; pp. 1-14.

39. Sonnino, R.; Marsden, T. Beyond the divide: Rethinking relationships between alternative and conventional food networks in Europe. J. Econ. Geogr. 2006, 6, 181-199. [CrossRef]

40. Yin, R.K. Case Study Research and Applications: Design and Methods; SAGE Publications Inc.: London, UK, 2017.

41. Eisenhardt, K.M.; Graebner, M.E. Theory building from cases: Opportunities and challenges. Acad. Manag. J. 2007, 50, 25-32. [CrossRef]

42. Eriksson, P.; Kovalainen, A. Qualitative Methods in Business Research; Sage: London, UK, 2016. 
43. Leca, B.; Gond, J.P.; Cruz, B.L. Building 'critical performativity engines' for deprived communities: The construction of popular cooperative incubators in Brazil. Organization 2014, 21, 683-712. [CrossRef]

44. Gioia, D.A.; Corley, K.G.; Hamilton, A.L. Seeking qualitative rigor in inductive research: Notes on the Gioia methodology. Organ. Res. Methods 2013, 16, 15-31. [CrossRef]

45. Böhm, S.; Dinerstein, A.; Spicer, A. (Im)possibilities of Autonomy: Social movements in and beyond Capital, the State, Development. Soc. Mov. Stud. 2010, 9, 17-32. [CrossRef]

46. Ilbery, B.; Maye, D. Alternative (shorter) food supply chains and specialist livestock products in the Scottish-English borders. Environ. Plan. A Econ. Space 2005, 37, 823-844. [CrossRef]

47. Diefenbach, T.; Sillience, J.A.A. Formal and informal hierarchy in differ types of organization. Organ. Stud. 2011, 32, 1515-1537. [CrossRef]

48. Nordin, F.; Ravald, A.; Möller, K.; Mohr, J. Network management in emergent high tech business contexts: Critical capabilities and activities. Ind. Mark. Manag. 2018, 74, 89-101. [CrossRef]

(C) 2019 by the authors. Licensee MDPI, Basel, Switzerland. This article is an open access article distributed under the terms and conditions of the Creative Commons Attribution (CC BY) license (http://creativecommons.org/licenses/by/4.0/). 